\title{
New procedures of ergonomics design in a large oil company
}

\author{
Cynthia Mossé Alhadeffa ${ }^{\mathrm{a},}$, Rosana Fernandes da Silva ${ }^{\mathrm{a}}$ and Márcia Sales dos Reis ${ }^{\mathrm{a}}$ \\ ${ }^{\mathrm{a}}$ Corporate Health Management, Petroleo Brasileiro S.A., Av. Almirante Barroso, 81-23․, CEP:20031-004, \\ Centro, Rio de Janeiro, RJ, Brazil
}

\begin{abstract}
This study presents the challenge involved in the negotiation and construction of a standard process in a major petroleum company that has the purpose of guiding the implementation of ergonomic studies in the development of projects, systemising the implementation of ergonomics design. The standard was created by a multi-disciplinary working group consisting of specialists in ergonomics, who work in a number of different areas of the company. The objective was to guide "how to" undertake ergonomics in all projects, taking into consideration the development of the ergonomic appraisals of work. It also established that all the process, in each project phase, should be accompanied by a specialist in ergonomics. This process as an innovation in the conception of projects in this company, signals a change of culture, and, for this reason requires broad dissemination throughout the several company leadership levels, and training of professionals in projects of ergonomics design. An implementation plan was also prepared and approved by the corporate governance, complementing the proposed challenge. In this way, this major oil company will implement new procedures of ergonomics design to promote health, safety, and wellbeing of the workforce, besides improving the performance and reliability of its systems and processes.
\end{abstract}

Keywords: projects, ergonomics design, standard procedure, multi-disciplinary, reliability

\section{Introduction}

The development of an Ergonomics programme in a major oil company requires wide ranging and structured initiatives for the feasibility of its implementation.

In general, in companies the focus of ergonomic studies are directed to the finding of solutions for emerging demands diagnosed in existing situations, the so called 'Corrective Ergonomics'. However, when there is a process of development of a new work situation, in the form of the creation of a new project, predicting problems along the length of its development is a good way to eliminate costs and obtain future benefits [1]. In this way, changes and revisions in the conditions and work processes can be re-evaluated and previously validated, before being implemented and financial investments effectively made.
The complexity of the preparation of a project, clearly indicates the need for the implementation of ergonomics in an articulated and pro-active form, taking into consideration the integration of the several disciplines which will be participating, as much in a project and/or in the construction of a Control room, as in a complete operational unit (platforms, refineries, thermoelectric power stations, ships, amongst others).

In this major oil company, the management in the area of security, environment and health (HSE), recognize the need to implement pro-active ergonomic initiatives in their several business areas, establishing internal objectives whereby Ergonomics is inserted in the planning, with a view to obtaining excellence in HSE. With the view to achieving this objective, the company adopts an HSE management standard for new business ventures, which establishes HSE actions in all the phases which make up the life cycle of a project. This essential condition has

*Corresponding author. E-mail: cmosse@petrobras.com.br; cmosse@gmail.com; Tel.: 5521 3229-2487 
simulated the need to prepare corporate guidelines directed to the application of Ergonomics Design.

The need to align the concepts and to disseminate the perspective of strategic planning led to the formation of a Work Group (WG) for the preparation of corporate guidelines. The group was made up of professionals predominantly with specialization in Ergonomics. In view of the diversity of the operational areas involved, this group was made up of representatives from all areas of the company of the company, with the objective of covering its different areas of specificity.

\section{The work group and the preparation of corporate guidelines of ergonomics design}

The work initiated by the group was based on studies previously prepared by specialists who had already been discussing the best forms of its application. These studies sought to customize the application of Ergonomic Analysis of Work in a broad sense, adopting the Ergonomic Analysis of Work - EAW in conformity with the manual of application Regulatory Norm: 17 - Ergonomics, a legal document whose text establishes minimum criteria of ergonomic conditions to be supervised by the Ministry of Labor in Brazil.

Although the Work Group had been formed by professionals with skills in Ergonomics, their graduate knowledge originated from different areas, such as: engineers in workplace security, doctors, architects and nurses. This diversity of skill formation enriched the work generating a number of different points of view and approaches.

The work methodology adopted was defined through monthly meetings, always on two full consecutive days. The execution of the agenda was based on the definition of the Ergonomic initiatives and their applicability in each phase of the life cycle of a project, and how to make its implementation feasible. Furthermore, initiatives were defined so that these initiatives would equally attend projects of reform and/or expansion of existing structures.

To keep a coherency regarding the initiatives being prepared, it was necessary to establish an Ergonomics appraisal methodology, and thus, it was consensually decided to proceed with EAW (Ergonomics Analysis of Work) [2].

The guidance of "how" to undertake EAW was considered the main axis, which would then subdivide into a focus on Corrective and Design
Ergonomics. The result of the work was defined as a Standard Process for the Application of Corrective and Design Ergonomics, to be implemented in all areas of the company.

A flowchart was evaluated, Figure 1, with the purpose of clarifying the methodology of application.

In the course of the work meetings, debates and research concerning the project practices were undertaken for guidance and to maintain the coherency of all the announced initiatives related to the carrying out of an EAW.

Attention is called to the contribution of professionals that made up the group with experience in the area of projects; they were very enriching since they had worked for many years in this area of the company. They offered the group a clear understanding of what takes place in each phase of a project [4], so that the building of guidelines on the Ergonomics Design could be thus better defined.

While the guidelines of how to proceed with the application of Corrective Ergonomics flows more easily since it is already an established practice in some of the company's business areas, the structuring of the focus on design was more complex, from the point of view of the latter being a formalization of initiatives to be followed by stages.

During the whole extent of the work, the group considered it essential to assure the participation of a specialist professional in Ergonomics to accompany all the phases of the project, in order to guide and supervise the implementation of the initiatives that were being announced. Thus, in the standard prepared, the necessary participation of a professional, specialist in Ergonomics was defined for the preparation of new business ventures. The understanding of the group was unanimous in establishing that a project professional graduated in Ergonomics had the necessary skill to articulate with all the responsible areas which were involved in the development of a project. The latter was a new factor in the proposal made by the group, leading to the creation of a new position, within a culture of project process developed and implemented by the company over the length of more than 50 years. The referred condition being equally supported by the HSE management standard for new company business initiatives, whereby HSE initiatives were established as attributes of the project managers, amongst them those related to Ergonomics.

Because of the short periods of time of the monthly meetings, the work of preparation of the Standard, estimated at six months, took longer, approximately 12 months. 


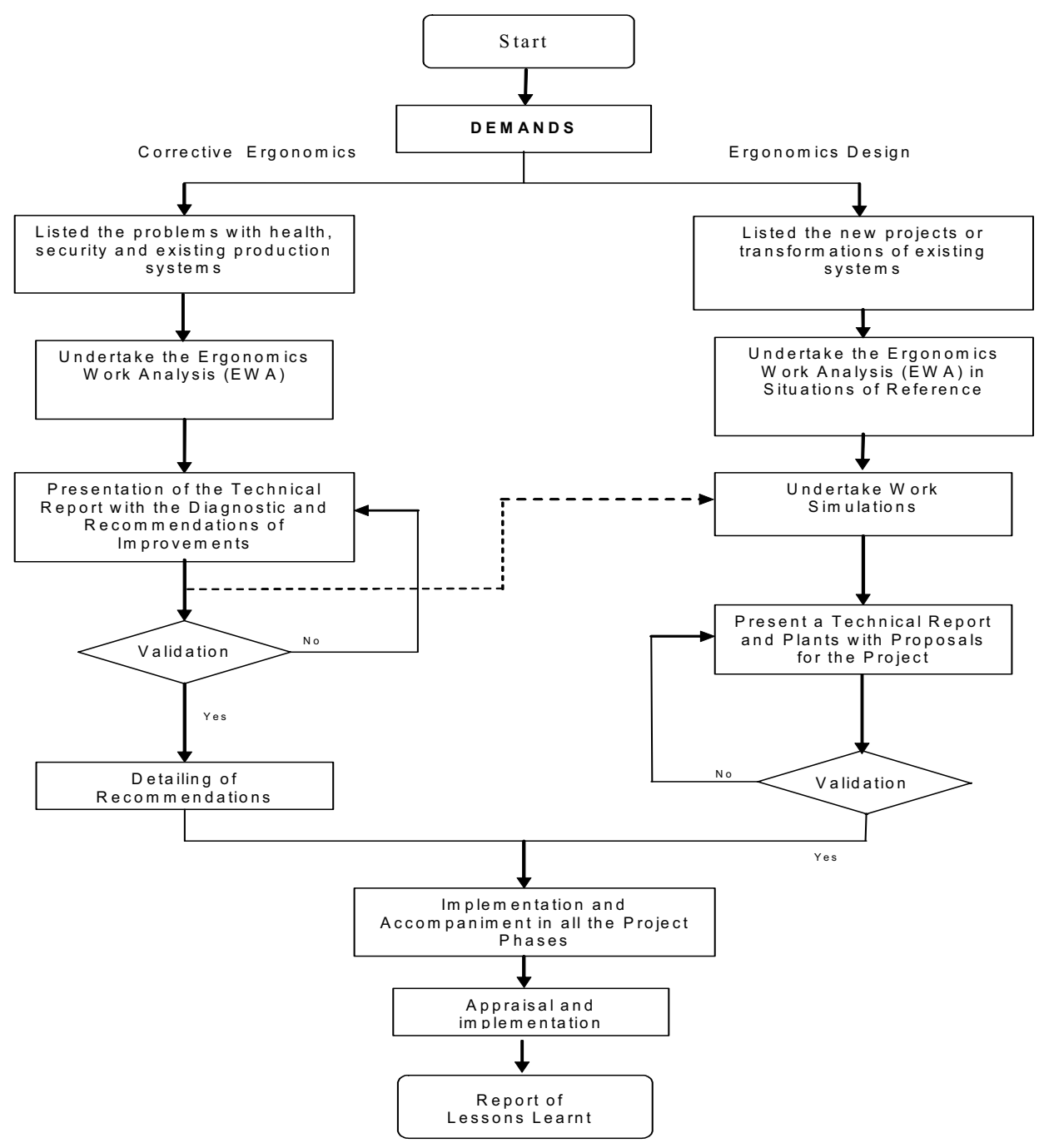

Figure 1

Flowchart of the Methodology of the Application of Design and Corrective Ergonomics reforms of existing Organizational Units, should occur, since their initial phases, enabling the

\section{Application of ergonomics focused on design}

Four parameters were recommended as a basis for the correct understanding of the application of Ergonomics design in the company, directing the usage of the methodology selected for the conceptual structure of the projects adopted by the company:

- Parameter 1: The undertaking of ergonomic studies for the projects of new installations, technological modernizations, expansions and/or conditions and the work processes to become more adequate for the development of the activities in a secure, healthy and efficient manner.

- Parameter 2: In the case of new installations, the mapping out of ergonomic aspects should be carried out in the previous phases related to the basic project, whereby the methodology of Ergonomic Analysis of Work (EAW) should be applied. 
- Parameter 3: The ergonomic initiatives in a project should necessarily have continuity in the several stages of execution of the project (detailing, implementation, assisted operation, operation and maintenance).

- Parameter 4: Methodologies of work simulation should complement the Ergonomic Analysis of Work (EAW) in the mentioned situations, in order to offer support to the models of future scenarios.

The Project structure in stages adopted in this company, follow a management approach called "Corporate Systemization for Project Investment", aligned with the Project Management Body of Knowledge -PMBOK of the American National Standard ANSI/PMI 99-001-2004-EUA. The structure of phases of the project used is equivalent to the Life Cycle of the Project and its Processes.

The planning and execution initiatives to be undertaken at each phase, according to a management standard for new HSE business projects, are as follows:

- Phase I: Identification and evaluation of opportunities: preliminary evaluation in order to generate the fundamentals and criteria of the project, as regards technology, location, investment, HSE, costs and planning. In this phase, the objectives of the project are traced and its pre-feasibility analysis prepared.

- Phase II Conceptual Design: Preparation of a Design Project (representing a pre-project).

- Phase III: Basic Project: finalization of the Project plan with the preparation of the Basic/Feed Project.

- Phase IV: Detailing and Implementation construction and assembly: on the basis of the Basic Project approved, the Executive Project is undertaken, the detailing stage itself. In this phase the mobilization of contractors and work site occur, including landfilling and civil construction, electro-mechanical assembly, apart from verifications and tests of installations and equipment.

- Phases V \& VI: Assisted Operation, Operation and Maintenance: at this stage there should be guarantee of compliance with the project specifications, and that the training of the teams that will be operate and maintain the installations has been duly carried out.

- Phase VII: Disassembling: Project disassembling (at the end of the life cycle of a project) and its execution.

\section{Requirements}

The application of Ergonomics Design in projects recommends the need for general and specific requirements.

\subsection{General requirements}

Pre-empting the guidelines of the procedure of "how" Ergonomics should be applied in the different phases of the Project, important requirements were made to align its application.

One of the main requirements was to maintain the alignment with the standard applied for the management of new business ventures, obtaining a coherency of HSE initiatives articulated with the project phases.

The guidance that EAW should always be undertaken in situations of reference involving the respective local workforce under study is one of the requirements which helps focus the vision to the reality of the situation being studied. Another important requirement is to use EAW as a means of identifying the main typical situations or typical action situations undertaken by the different workers (from production, maintenance, utilities and others) such as: stops, starts, change of raw material, product specification changes, technological changes, and abnormalities, amongst others. It should be borne in mind that the identification of these typical situations contributes to the preparation of future activity scenarios, which support the analysis of project objectives.

The Project objectives should be analyzed right from the initial stages using simulation techniques that demand supporting materials like, plants, models both physical and/or electronic, prototypes and others. This is a requirement that should count with the participation of future users, of project designers and specialists in Ergonomics responsible for EAW.

To assure that the objectives are validated and consolidated with the future users and to guarantee the integrity of the project using a specialist in ergonomics to accompany the several stages of execution of the project, serves to complement the general requirements for the application of Ergonomics in the life cycle phases of the project. 


\subsection{Specific requirements}

Some conditions complement the general requirements for the application of the Ergonomics design, related to co-responsibilities.

The manager responsible for the project is the person who should assure the participation of the specialist in Ergonomics accompanying all the phases of the project, as established in the management standard for new business ventures, defined by means of a table of responsibilities and attributes related to new business ventures.

In order that HSE management can keep control of the accompaniment of the application of Ergonomics Design, in compliance with what is stated in the management standard for new business ventures, it was established that in each phase an HSE report should be generated containing ergonomic information according to a routine prepared by the work group.

Among the activities and responsibilities of the specialist professional in Ergonomics indicated to accompany the project, attention is called to the situation whereby he or she should identify the demands stemming from the particularities of each project.

The project professionals involved should receive basic training in Ergonomics Design, as a complementary requirement for the development and application of Ergonomics Design.

\section{Ergonomic studies in the different project phases}

The initiatives prepared by the work group that consist of the guidelines for the application of Ergonomics Design in each phase of the project under the responsibility of the ergonomist are as follows:

- Phase 1 - Identification and evaluation of opportunities: Undertake the identification of the relevant points that might require more specific action from the Ergonomics specialist, with the objective of predicting the necessary investment right from the initial phase. For example: importing of new technologies (adaptation of the installations to the local anthropometric standards, initial difficulties of the operation) and big ergonomic risks (inadequate positioning and access to valves and instruments, congested escape routes, work in integrated control centres and confined locations). In case the necessary information in this phase has still not been consolidated, the participation of the Ergonomics specialist should start in Phase II, by which time the definitions will already have been established, and from then on, should be considered as guidelines for the above described initiatives.

- Phase II - Design Project: In this phase the scope of the ergonomic study should be defined as a result of the necessities identified in Phase I, its stages, as well as the documents that should make up the ergonomic study (chronograms, mapping out of situations of reference, etc). The Ergonomic services forecast for the next phase, Phase III, should be listed, with a view to offering supporting budget estimate information.

- This phase can be the initial one for the activity of the Ergonomics specialist related to the forecast of investments and the identification of relevant points, in the case that in Phase I, necessary information had still not been defined.

- Phase III - Basic Project: Undertake Ergonomic studies, EAW, according to what was defined in Phase II. To complement the studies one should:

* assist with the procurement of equipment, as regards the compliance with ergonomic criteria;

* identify with the operational areas, the critical points to receive priority for the ergonomic study;

* verify the processes, operational routines (including those of maintenance) and technologies that will be used in the new business ventures, as well as the dimensioning of the workforce and the situation of reference to be studied.

* consider the facilities for future operations during the disassembly and dismounting (project disassembly) in such a way as to avoid/minimize the ergonomic risks;

* verify in the situations of reference, the following data, when applicable: information concerning the work system, characteristics of the workforce (bearing in mind the Laws in force or at international level, the document that contemplates the care with access of people with disabilities or reduced mobility, when applicable), environmental aspects, biomechanical demands, information concerning the organizational structure, rhythm, workday, 
distribution of work, physical arrangement and cognitive aspects present;

* prepare a Report of the Analysis of Activities of the situation of reference, which should be validated with the users (representative fraction);

* validate with users and with a project team the problems raised and the ergonomic technical recommendations to be considered in the detailing phase and;

* prepare a Final Ergonomic Study Report.

- Phase IV - Detailing and Implementation: Accompany the progress of the project in such way as to guarantee the actuality of the ergonomic report, in view of the need for changes that can occur in this phase of the project. Whenever necessary, obtain with the project team, solutions for the eventual necessary adaptations as a result of the interferences, changes in technology, lack of initially specified material, lack of technical feasibility or cost aspects and timing aspects that might occur in the preparation phase of project detailing. In this phase the ergonomic recommendations should be detailed through the specific techniques, arrangements, details of installations, list of materials, electronic model, prototype and other resources that may be necessary. Any purchase of equipment in this phase, should be given assistance as regards ergonomic criteria. During the construction and assembly, the implementations recommended in the ergonomic report should be accompanied, as well as any adaptations that may be necessary, in such a way as to guarantee the integrity of the ergonomic project. This accompaniment also has the purpose of initiating the mapping of the lessons learnt, which contribute to future projects; for this reason it is important to prepare the register of the alterations, in the case that there are divergences between the ergonomic project and the executed project, after the end of the implementation process.

- Phase V e VI - Assisted Operation, Operation and Maintenance: Evaluation of the results obtained, validating the project. This information should be registered in the report of the lessons learned to serve as reference for the next new business ventures.

- Phase VII - Disassembly: Avoid and/or minimize the possible ergonomic deviations that can occur in this phase, for example: difficulties in the disassembly and removal of installations, units and equipment, predicting the appropriate means (tools, equipment, and accesses) for the referred tasks.

\section{The implementation of the corporate standard}

After the process of approval of the standard, the work group prepared a plan for its implementation beginning in 2009 .

In this plan initiatives are included such as basic knowledge of Ergonomics design for professionals involved in the project, communication by divulging to managers, ergonomic teams and professionals involved in projects and new business ventures. An accompaniment was also forecast for later critical analysis of the plan.

The professionals that participated in the Work Group prepared the content of the course syllabus for the training of the project professionals. This course was included in the rank of regular courses offered by the company and coordinated by the corporate area responsible for the management of the corporate ergonomics programme. Since it is a course that lasts just 40 hours it has been possible to get several groups per year to undertake it, in this way covering a greater number of professionals from the various knowledge areas that make up the project requirement. Three groups have already undergone training with the participation of professionals involved in the projects, such architects, engineers of several specializations, nurses, and physiotherapists; furthermore operators and/or users of specific project situations that are now operational and others underway.

The standard predicts revision systemization, and at the moment it is in initial implementation phase throughout the company.

In alignment with the objective of achieving excellence in HSE, all corporate areas agreed to gradually incorporate Ergonomics design with the introduction of at least 01 pilot project until 2015.

Nevertheless, a practice already initiated in this company to stimulate the integration of ergonomic studies in projects should be noted: in every new business venture above a certain value, a technical opinion should be requested from the corporate area responsible for the Ergonomic Programme with purpose of undertaking an appraisal and/or to obtain pertinent guidance, according to the specificity of each project, so that certain already recognized work 
situations with potential demands requiring special attention in terms of Ergonomic aspects and demands, can be studied and observed.

At the moment, the corporate ergonomics team is accompanying the implanting of a pilot implementation of the Ergonomics design standard in a refinery.

\section{Conclusion}

The studies of experiences in the present scenario indicate a growing concern in organizing the structures of the project design teams, more so than those related to corrective ergonomics - a practice more divulged and integrated in the reality of the ergonomic initiatives within the company. Even so, the latter needs guidance and accompaniment of an ergonomist who has the vision of processes and accompanies the activity involved in the situation in which changes will be undertaken.

The sustainability and continuity of the initiatives in this area gain force when the several areas of interest (health, engineering, security, human resources, and projects, among others) become integrated and several players contribute to the development of projects of new business ventures. This understanding became consolidated with the experience shared by different professionals who participate in this challenge.

Building compliance to the guidelines that make up the standard for the Application of Design and Corrective Ergonomics in a major oil company has been an inedited experience for all the professionals in Ergonomics, participants of the work group, as well as a great conquest for the production process.

The guidance of the participation of a specialist in Ergonomics in the implementation of the prepared initiatives, and the training in Ergonomics Design of the project professionals, can be considered the factors that stand out from the standard prepared by the group.

It is also necessary that over the length of development of the critical analysis that will accompany the implementation process of the prepared standard, the results obtained be observed as much in the operational processes as well as in the optimization of costs related to the increase in production, in security and in operational reliability.

To incorporate these stages to a project and to conceptualise them as being best practice to be referred to is also a concern of the professionals that participated in the technical group.

The above initiative has received support and recognition on the part of the corporate leadership who is - to a greater extent - responsible for the consolidation of these initiatives and guarantors of the implementation of the guidelines concerning Design and Corrective Ergonomics, which assures the technical staff a positive outlook for advances in this area.

\section{References}

[1] Duarte, F. Ergonomia e Projeto na indústria de processo contínuo (org.), Rio de Janeiro: COPPE/RJ: Lucerna, 2002. $312 \mathrm{p}$.

[2] Guérin, F. Compreender o trabalho para transformá-lo: a prática da ergonomia, São Paulo: Edgard Blücher: Fundação Vanzolini, 1991.

[3] Hendrick, H.W. Boa Ergonomia é Boa Economia, Recife-PE: ABERGO,2003 - Texto de Palestra publicado com a permissão do Prof. Hal W. Hendrick.

[4] Santos, N. (et al). Antropotecnologia: A Ergonomia dos Sistemas de Produção, Curitiba: Gênesis, 1997. 354p.

[5] Wisner, A. A inteligência no trabalho, São Paulo: FUNDACENTRO, 1994. 191p. 